\title{
pro.posições
}

http://dx.doi.org/10.1590/1980-6248-2021-0075

DOSSIÊ: "Paulo Freire e a Educação: cem anos de dialogação, problematização e transformação"

\section{Didática-criação: uma perspectiva freiriana 1234}

\section{Didactics-creation: a Freirian perspective}

Irène Pereira (i)

(i) Institut National Supérieur du Professorat et de l'Éducation ${ }^{5}$ - Inspé de l'Académie de Créteil; Bonneuil sur Marne, France. http://orcid.org/0000-0002-1243-1188, ir_pereira@yahoo.fr.

\begin{abstract}
Resumo
Este artigo, na continuidade da obra de Paulo Freire, tomada como uma pedagogia emancipatória, propõe desenvolver uma perspectiva estética para a pedagogia crítica, através de uma didática-criação, derivada da noção de pesquisa-criação, que propõe uma articulação entre as investigações no campo das ciências sociais e a dimensão artística. O texto critica a adoção da dimensão estética na perspectiva puramente técnica, visto que na sociedade capitalista também a arte e o estético foram instrumentalizados pelo capital, reivindicando um agir ético como aquele que pode fazer frente a tal realidade. A didática-criação é apresentada em sua dimensão teórica e são apresentados seus usos práticos em uma pedagogia crítica. Ao longo do artigo, colagens digitais são introduzidas para ilustrar as questões trabalhadas.

Palavras-chave: pedagogia crítica, estética, agir ético, didática-criação, Paulo Freire.
\end{abstract}

\footnotetext{
${ }^{1}$ As pesquisas apresentadas neste artigo são realizadas em seu tempo pessoal por uma pessoa sem cargo estatutário e institucional de docente-pesquisador. Esta observação tem por objetivo dar visibilidade à falta de postos de trabalho no campo da pesquisa na França.

2 Tradução de Silvio Gallo e Alexandre Filordi de Carvalho.

${ }^{3}$ Editor responsável: Silvio Donizetti de Oliveira Gallo. https://orcid.org/0000-0003-2221-5160

${ }^{4}$ Normalização, preparação e revisão textual: Lídia Orphão (Tikinet) - revisao@tikinet.com.br

${ }^{5}$ Chercheuse non-rémunérée
} 


\section{pro.posições}

http://dx.doi.org/10.1590/1980-6248-2021-0075

\begin{abstract}
In continuation of Paulo Freire's work, taken as an emancipatory pedagogy, this work proposes to develop an aesthetic perspective for critical pedagogy. To this end, it relies on a didactic-creation, derived from the notion of research-creation, which proposes an articulation between investigations in the field of social sciences and the artistic dimension. Considering that, within a capitalist society, art and the aesthetics were also instrumentalized by capital, the text criticizes the adoption of the aesthetic dimension in a purely technical perspective, claiming an ethical action as one that can deal with such reality. Through a theoretical dimension, this study presents the didactics-creation and its practical uses in a critical pedagogy, introducing digital collages to illustrate the issues addressed.
\end{abstract} Keywords: critical pedagogy, aesthetics, etbical acting, didactic-creation, Paulo Freire

O sucesso da expressão "caixa de ferramentas conceituais" [Foucault] nos últimos anos o exprime perfeitamente: a bistória da filosofia apresenta-se como um depósito de livre acesso, no qual basta escavar com a certeza de que os "bons pensamentos" estejam bem indicados. Tal ideologia da apropriação, também frequente na arte, não é nova. Ao contrário, parece-nos que ela não faz mais que exprimir a etimologia do modo de produção capitalista: acumulação e rapina.

(Samuel Zarka, Art contemporain: Le concept, 2010)

\section{Introdução}

Neste ano de centenário do nascimento de Paulo Freire, gostaríamos de recordar sua contribuição a uma pedagogia crítica visual criativa e propor algumas pistas de continuações práticas de sua perspectiva através daquilo que denominamos como didática-criação. Porém, os desafios de nosso artigo não estão em falar propriamente em proposições práticas. Trata-se, antes, de uma reflexão sobre a recusa expressa em várias ocasiões por Paulo Freire, em particular aos educadores e às educadoras estadunidenses, em fornecer técnicas, ferramentas ou métodos (Freire, 2019). 


\section{pro.posições}

http://dx.doi.org/10.1590/1980-6248-2021-0075

Isso se explica, em nosso modo de ver, como ele repetiu em múltiplas ocasiões, pelo fato de a pedagogia crítica não ser um "agir técnico" (em grego, technê), mas um "agir ético" (em grego, praxis). Isto é muito bem ilustrado por sua última obra publicada em vida, Pedagogia da autonomia (Freire, 2013), que não contém qualquer ferramenta, mas na qual a palavra "ética" aparece mais de 150 vezes; não se trata, porém, de qualquer ética. Não é à ética utilitarista do mercado que ele fala, mas de uma "ética da crítica" (Pereira, 2019). Portanto, consideramos necessário, a fim de evitar a confusão entre o agir técnico e o agir ético, denominar didática aquilo que põe acento no agir técnico e denominar pedagogia aquilo que destaca o agir ético.

De nossa parte, denominamos "didática-criação" um conjunto de proposições didáticas que têm por objetivo operar um processo de conscientização ${ }^{6}$. A noção de criação remete ao fato de que se trata de apoiar-se nas práticas de criação artística. Por que nos referimos às práticas artísticas? Se partimos da Teoria do Agir Comunicativo de Jurgen Habermas (1987), podemos distinguir três formas de ação: o agir estratégico (ou agir técnico), o agir regulado (ou agir ético) e o agir dramatúrgico (ou agir estético [em grego, poiesis]). Como se sabe, a Teoria Crítica da Escola de Frankfurt enfatizou que a modernidade se caracteriza por um processo de colonização do conjunto das esferas da existência pela dominação do agir instrumental (isto é, um agir técnico). Por essa razão, o agir estético, como o agir ético, poderia constituir uma via de tentativa de resistência à dominação da racionalidade instrumental no domínio educativo. Com efeito, o valor estético de uma obra não se reduz a seu valor instrumental, isto é, à busca de eficácia, ainda mais na era neoliberal, à busca de eficiência. Neste artigo, contudo, frente a esta hipótese, seremos levados a colocar em destaque os limites desta perspectiva. De fato, o agir estético comporta uma dimensão técnica presente desde a origem da noção de arte. Sublinharemos como o capitalismo soube instrumentalizar a criação artística e como toda perspectiva de didática-criação está sob o risco de uma captura capitalista.

\footnotetext{
${ }^{6}$ Este artigo retoma múltiplos elementos de uma pesquisa em curso em nosso caderno de pesquisa Hypothèses, Les Cabiers de pédagogies radicales. Por isso, serão encontrados aqui trechos retomados de notas de pesquisa preparatórias que aparecem em nosso caderno. Dossiê "Didática-criação": https://pedaradicale.hypotheses.org/tag/didactiquecreation
} 


\section{pro·posições}

http://dx.doi.org/10.1590/1980-6248-2021-0075

Por isso, defenderemos a ideia de que, definitivamente, sem um agir ético que oriente e normatize o uso das práticas de didática-criação, elas não se distinguem de sua captura instrumental pelo capitalismo. De modo geral, afirmaremos que assistimos hoje a um retorno das reivindicações éticas, compreendidas pelos trabalhadores e pelas trabalhadoras do meio artístico como tentativa de resistência à dominação do tecnocapitalismo.

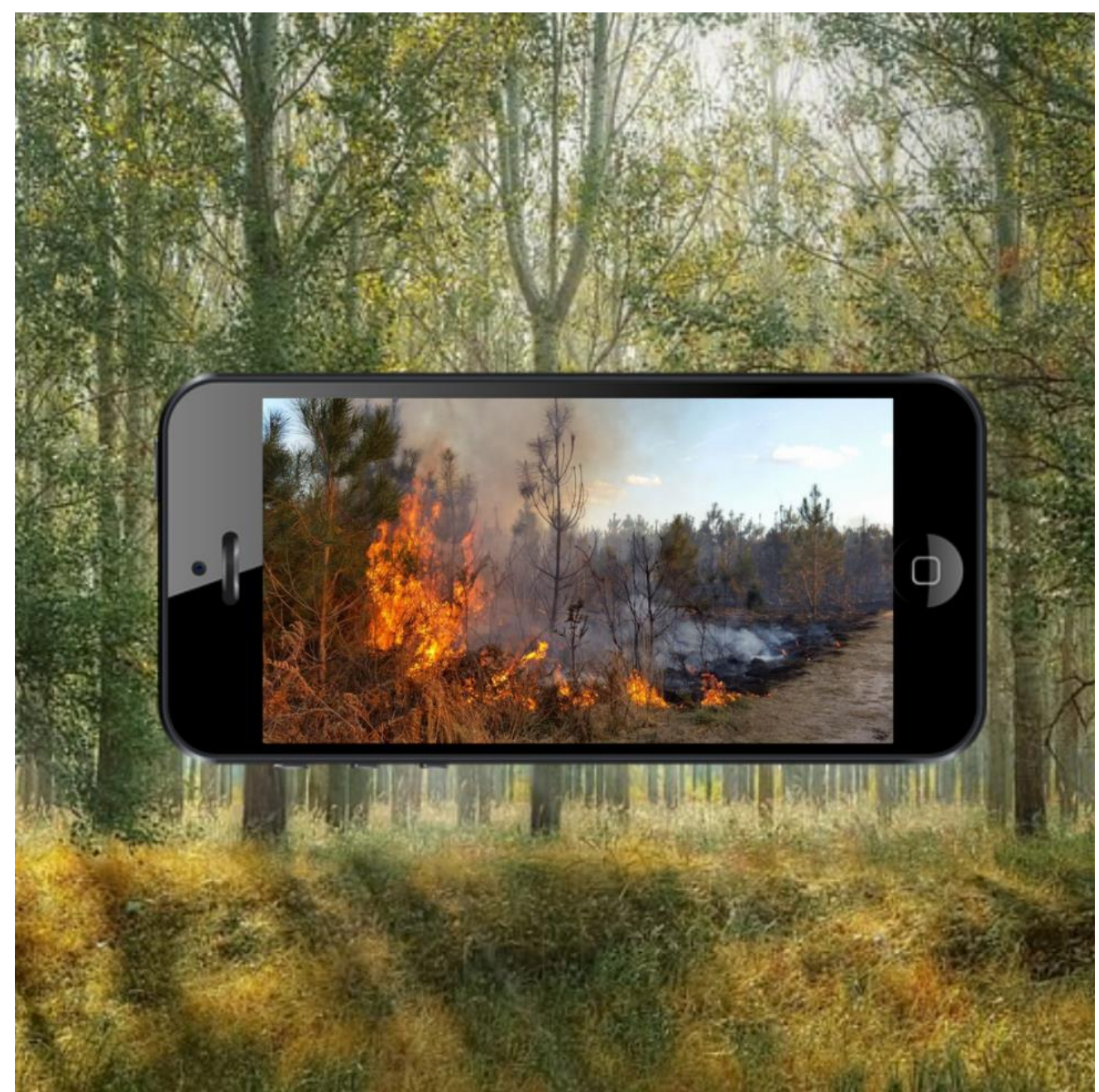

Figura 1 - Incêndio ${ }^{7}$

\footnotetext{
${ }^{7}$ Observação: o artigo será ilustrado por diversas colagens que realizamos com o objetivo de mostrar a abordagem da didática-criação. As fotografias que servem de base às colagens foram tomadas de bancos de imagens livres de direitos, particularmente Pixabey.
} 


\section{pro.posições}

http://dx.doi.org/10.1590/1980-6248-2021-0075

\section{Elementos de história das práticas artísticas na perspectiva da pedagogia crítica}

Paulo Freire utilizou a imagem como suporte da discussão, mas foi além, usou-a como suporte de conscientização. Na Polônia, ele solicitou retroprojetores de slides. Ele fez produzir séries de imagens que representavam os universos temáticos das pessoas com as quais trabalhava ${ }^{8}$. A pedagogia do oprimido foi, então, inovadora no uso da imagem, mas igualmente no recurso à criação artística como suporte de conscientização. Além disso, em Pedagogia do Oprimido (1974) Paulo Freire dá importância à imaginação criadora com a noção de "inédito possível", que consiste em imaginar outras realidades possíveis, para além daquelas que estão dadas nas situações-limite (isto é, a realidade social que os oprimidos enfrentam). Pode-se, então, recordar a concepção de Paulo Freire do "Princípio de esperança" de Ernst Bloch (Girox \& McLaren, 1997). Paulo Freire aceitou o qualificativo de utópico:

Para mim o utópico não é o irrealizável; a utopia não é o idealismo, é a dialetização dos atos de denunciar e anunciar, o ato de denunciar a estrutura desumanizante e de anunciar a estrutura humanizante. Por esta razão a utopia é também um compromisso histórico.

A utopia exige o conhecimento crítico. É um ato de conhecimento. Eu não posso denunciar a estrutura desumanizante se não a penetro para conhecê-la. Não posso anunciar se não conheço, mas entre o momento do anúncio e a realização do mesmo existe algo que deve ser destacado: é que o anúncio não é anúncio de um anteprojeto, porque é na práxis histórica que o anteprojeto se torna projeto. (Freire, 1979, p. 16)

Com efeito, a imaginação utópica é uma marca crítica capaz de recusar o fatalismo, inclusive o neoliberal, como disse Margaret Thatcher: "não há alternativa".

O elo entre pedagogia crítica e arte encontra-se presente no teatro do oprimido de Augusto Boal. Trata-se particularmente de retomar a noção de "estética do oprimido" de Boal. Tal noção foi teorizada pelo autor como resistência à perda de aura da obra de arte na sociedade tecnocapitalista, descrita por Walter Benjamin (2013) em A obra de arte na época da reprodutibilidade técnica. Em sua Estética do oprimido, Boal afirma o caráter emancipador da criação artística e do fato de que cada um e cada uma torna-se criador e criadora; é a "multiplicação dos artistas":

\footnotetext{
${ }^{8}$ Neste link, encontramos os documentos visuais usados por Freire e sua equipe, particularmente durante a célebre experiência de alfabetização em Angicos (Brasil): http:// forumeja.org.br/book/ export/html/1412
} 


\section{pro.posiçōes}

http://dx.doi.org/10.1590/1980-6248-2021-0075

Queremos promover a multiplicação dos artistas. São os artistas, eles próprios, que se multiplicam, não suas obras copiadas. Não se podem fazer cópias de um ser humano - cada um é único e essa é sua aura, ou dela é parte. (Boal, 2009, p. 46)

Na continuidade de Paulo Freire, além da de Augusto Boal, poderíamos citar ainda outras abordagens que tendem a utilizar práticas de criação artística para produzir um processo de conscientização.

Encontra-se igualmente uma abordagem de tipo artístico no uso da fotografia na photovoice (fotovoz) (Vandette et al., 2014). Este método de pesquisa-ação integra a fotografia, podendo assim dar lugar a uma dimensão estética, mesmo que ela não esteja em primeiro lugar sob o ângulo que é abordada. A photovoice foi criada pelas universitárias Caroline Wang e MaryAnne Burris nos anos 1990, nos Estados Unidos. Podemos aproximar este método de pesquisa participativa de uma outra técnica de pesquisa, a fotoelicitação. $\mathrm{Na}$ photovoice, trata-se de solicitar às pessoas de comunidades socialmente marginalizadas para tirar fotografias sobre uma temática. Tiradas as fotografias, há uma organização em grupos de discussão orientados para a análise dos problemas e para a transformação social. As fotografias tiradas e as análises produzidas pelos e pelas participantes podem em seguida ser organizadas em uma exposição.

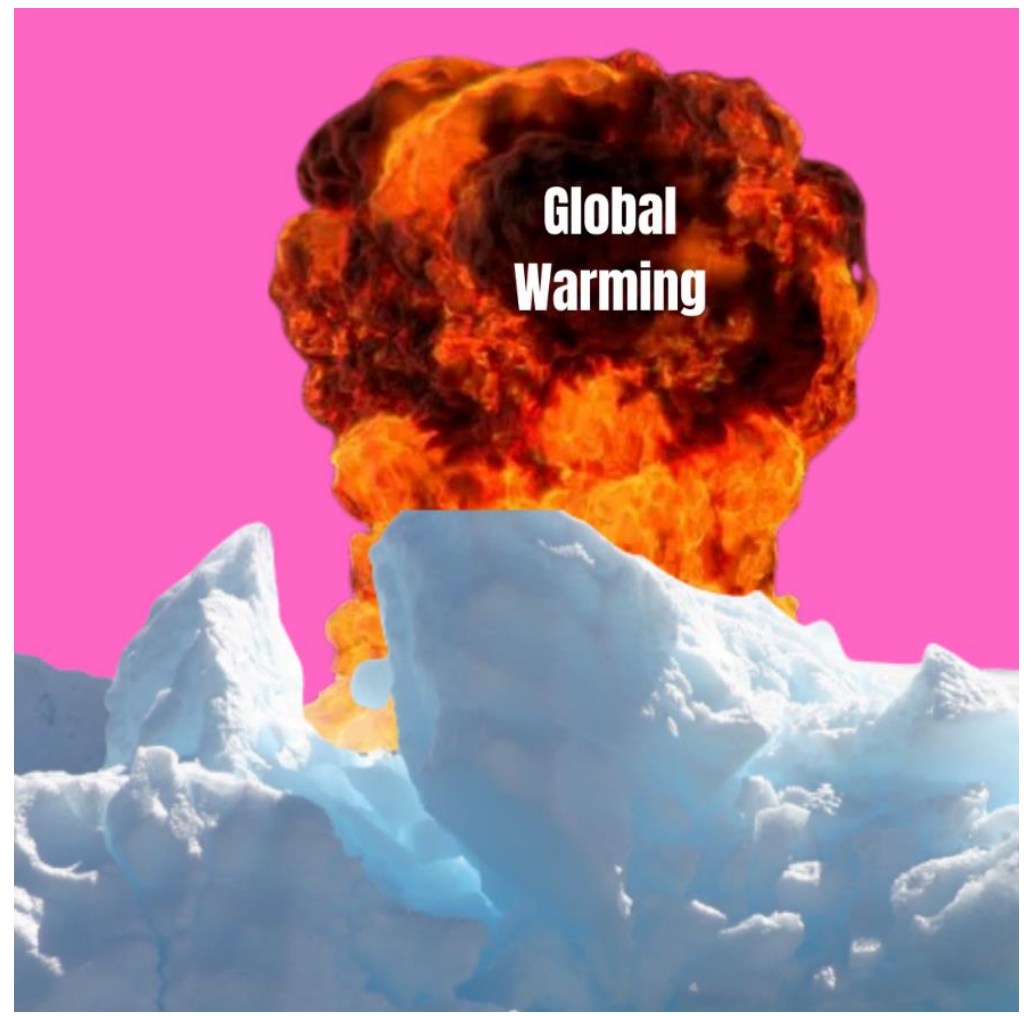

Figura 2 - Aquecimento do clima 


\section{pro.posições}

http://dx.doi.org/10.1590/1980-6248-2021-0075

\section{A didática-criação: uma abordagem na continuidade de Paulo Freire}

Não nos é possível, neste artigo, apresentar todas as criações que realizamos em didáticacriação, particularmente porque várias proposições foram realizadas em formato de vídeo? Limitar-nos-emos a dar uma visão geral dessas abordagens.

\subsection{Definição da didática-criação}

A noção de pesquisa-criação pode ter diferentes acepções. Trata-se especialmente de uma noção que foi desenvolvida no Canadá, que consiste em estabelecer cruzamentos entre a pesquisa em ciências sociais e a criação artística. Partindo disso, a pesquisa-criação toma duas formas. Trata-se de uma pesquisa em artes e ciências sociais realizada por artistas, ou uma pesquisa desenvolvida em ciências sociais que incorpora processos de criação inspirados em abordagens artísticas (Giacco et al., 2020).

A noção de didática-criação designa uma abordagem que se aproxima da pesquisacriação em ciências sociais. Trata-se de imaginar abordagens didáticas que integrem a criação artística. Contudo, a didática-criação não é uma didática das artes plásticas, mas sim abordagens didáticas que recorrem aos processos de criação artística em outras disciplinas, para além das disciplinas artísticas ou em abordagens mais gerais. De modo amplo, a didática-criação interessase pela maneira através da qual as práticas artísticas são integradas em laços com outras disciplinas ou domínios de aprendizagem através da escrita, dos exercícios teatrais, do desenho, da fotografia, do vídeo etc.

Mais particularmente, a didática-criação abrange a utilização de práticas de criação de modo a favorecer um processo de conscientização. Pode ser uma conscientização relativa às desigualdades sociais, por exemplo, às discriminações, aos problemas ecológicos ou a outros problemas sociais ligados às tecnologias, à sociedade de consumo e assim sucessivamente.

\footnotetext{
9 Para conhecimento, remetemos para o canal de vídeo do Institut de Recherche sur les Mouvements Sociaux (IRESMO): https://www.youtube.com/channel/UCfB8k7wWf1trZ6dxS43Iw1Q.
} 


\section{pro.posições}

http://dx.doi.org/10.1590/1980-6248-2021-0075

\subsection{A estética do/a oprimido/a}

A noção de didática-criação tal como a concebemos baseia-se sobre o que denominamos "Manifesto da estética do/a oprimido/a". Não pretendemos, neste manifesto, retomar exatamente a ideia de Augusto Boal, cuja obra refere-se mais à arte participativa do que ao que definimos no "Manifesto da estética do oprimido". O objetivo deste manifesto é sobretudo o de distinguir a estética do/a oprimido/a de outras concepções de arte conscientizadora produzidas por um artista. É o caso, por exemplo, das obras do artista de rua Bansky. A arte comunitária constitui-se numa proposta de arte conscientizadora na qual um artista profissional trabalha em conjunto com uma comunidade. O manifesto da estética do/a oprimido/a dirigese, por sua vez, a pessoas que não são artistas, no sentido especializado que é dado atualmente a este termo.

\subsubsection{O manifesto da estética do/a oprimido/a}

1. A estética do/a oprimido/a refere-se a Augusto Boal que, por sua vez, refere-se a Paulo Freire. Mas a estética do/a oprimido/a não se limita ao teatro.

2. A estética do/a oprimido/a não é uma estética estetizante. Ela visa à conscientização sobre as injustiças sociais e à transformação social. A conscientização pressupõe a problematização da realidade social. A transformação social implica na recusa da realidade social injusta.

3. A estética do/a oprimido/a não é uma estética para Artistas. O artista é aquele ou aquela que possui uma mestria técnica e/ou um conhecimento da história da arte.

4. A estética do/a oprimido/a não é um artivismo (artivisme) no sentido em que o artivismo seria uma prática na qual um Artista realiza uma obra visando a conscientização.

5. A estética do/a oprimido/a não é uma arte comunitária, no sentido em que denominamos "arte comunitária" uma prática artística com objetivo conscientizante produzida por um Artista com uma comunidade. 


\section{pro.posições}

http://dx.doi.org/10.1590/1980-6248-2021-0075

6. O/a oprimido/a é toda pessoa ou grupo de pessoas que necessitam desenvolver uma capacidade de reflexão crítica, de expressão e de ação com vistas à transformação social. As criações podem ser individuais ou coletivas.

7. Entretanto, estaríamos equivocados em pensar a ação como uma ação orientada pelo agir instrumental, pela dominação da racionalidade instrumental. $\mathrm{O}$ agir da estética do/a oprimido/a destaca uma forma de otium, uma relação com o mundo e consigo mesmo que não está orientada para a eficácia ou, ainda pior, a eficiência. Porque as práticas da estética do/a oprimido/a têm um valor nelas mesmas, independente mesmo da finalidade a que se destinam.

8. As práticas criativas levadas a cabo na estética do/a oprimido/a não pressupõem uma competência técnica prévia. São, por exemplo: a micronarrativa, a micropoesia, a colagem, a apresentação sonorizada de imagens, a fotonovela etc. Elas também não pressupõem um material caro.

9. As criações conscientizadoras, produzidas na estética do/a oprimido/a, têm por objetivo favorecer a reflexão crítica, o diálogo e a transformação social.

10. A estética do/a oprimido/a é posta em cena em um contexto educativo qualquer, mas não no quadro do ensino de Arte. O ensino da Arte se refere a uma competência técnica e a critérios reconhecidos pelo campo da Arte.

11. A estética do/a oprimido/a não é uma recusa em si do Artivismo ou da Arte comunitária, mas uma outra proposta.

\subsection{Práticas que não pressupõem uma competência técnica prévia}

A didática-criação implica em recorrer às práticas que não supõem o domínio pelos e pelas participantes de competências técnicas prévias, que impediriam uma entrada rápida na atividade ou que empregassem materiais caros. Neste aspecto, podemos aproximar a didáticacriação da arteterapia. Nesta, trata-se de fazer com que se possa privilegiar as práticas que demandam pouca competência técnica prévia como a pintura de desenhos. 


\section{pro.posiçções}

http://dx.doi.org/10.1590/1980-6248-2021-0075

A didática-criação é constituída por práticas que visam criar experiências conscientizadoras, particularmente pela escrita e/ou pelas artes visuais (fotografia, vídeo etc.).

De modo geral, podemos considerar que o teatro do oprimido ou o rap consciente podem ser abordados como práticas de didática-criação, quando eles são postos em cena em um contexto educativo. Como explica Paulo Freire a respeito dos suportes visuais que ele utilizava nos círculos de cultura, as imagens não deveriam ser diretivas, mas, ao contrário, deveriam favorecer a abertura da discussão. Contudo, à diferença do modo utilizado por Freire de solicitar a um artista especializado criar as imagens que serviriam de suporte à discussão, aqui são os educadores e educadoras e/ou o público com o qual trabalham que o farão.

Vejamos algumas práticas que podem ser consideradas como viáveis para trabalhar com pessoas que não possuam uma formação artística prévia:

- A micronarrativa ${ }^{10}$ : ainda que a micronarrativa exista há tempos na literatura, ela não teve um reconhecimento enquanto gênero específico senão com seu desenvolvimento na Internet e por escritores e escritoras amadores. Depois disso, algumas editoras passaram a publicar micronarrativas de autores reconhecidos. A micronarrativa é uma narrativa que comporta entre 140 caracteres e 1.000 palavras.

- A micropoesia ${ }^{11}$ : a micropoesia é igualmente um gênero que se desenvolveu bastante através da Internet, por exemplo, no Twitter. Baseia-se frequentemente em formatos da poesia japonesa, como o hai-kai (3 versos) e o gogyohoka (5 versos livres).

- Máximas e aforismos filosóficos ${ }^{12}$ : a escrita criativa pode valer-se também da criação nãoficcional, por exemplo, da criação na escrita filosófica, privilegiando as formas curtas como as máximas morais ou éticas ou ainda os aforismos filosóficos.

- A colagem ${ }^{13}:$ a colagem é frequentemente associada aos movimentos artísticos de vanguarda do século XX (por exemplo, cubismo, surrealismo, construtivismo,

\footnotetext{
10 Didática-criação: Microficção e apresentação de imagens sonorizadas (https://pedaradicale.hypotheses.org/3225).

11 Didática-criação: poesia e fotografia (https://pedaradicale.hypotheses.org/3212).

12 Didática-criação: aforismas e apresentação sonorizada-colagem (https://pedaradicale.hypotheses.org/3385).

${ }^{13}$ Didática-criação: ecologia e colagens pós-surrealistas (https://pedaradicale.hypotheses.org/3256).
} 


\section{pro.posições}

http://dx.doi.org/10.1590/1980-6248-2021-0075

dadaísmo, novo realismo etc.). Conheceu igualmente popularidade on-line, particularmente nas redes sociais como Instagram, ou ainda na arteterapia.

- A fotonovela e os quadrinhos ${ }^{14}$ : são dois gêneros populares. Encontramos on-line inúmeros programas que permitem produzir quadrinhos e fotonovelas. A narrativa pode ser construída sob a forma de uma prancha com diversos casos, ou sob a forma de uma apresentação de imagens (eventualmente sonorizada com animações).

- A apresentação de imagens sonorizadas (diaporama) ${ }^{15}$ : trata-se de uma narrativa curta composta por fotografias acompanhadas ou não de som, de texto ou ainda de vídeo. Este tipo de apresentação convém, por exemplo, à criação de "storytelling digitais", que são narrativas produzidas por pessoas pertencentes a grupos socialmente marginalizados.

Além disso, é possível usar recursos de mídias artísticas mistas, quer dizer, a combinação de várias destas técnicas: colagem e poesia, apresentação de imagens sonorizadas e micronarrativas e assim por diante.

\subsubsection{Um exemplo: as/os resistentes (microconto filosófico) ${ }^{16}$}

Progressivamente, o agir técnico colonizou o conjunto da existência. Os dias foram enquadrados pela quantificação do tempo. Mais e mais, as telas invadiram suas existências, seja durante o trabalho, seja no tempo livre. Uma injunção em direção à eficácia, e ainda mais à eficiência, dominou suas horas de trabalho. O tempo restante era ocupado pela diversão e pelo consumo.

Asseguraram-lhes que o capitalismo verde regeneraria o planeta, recriando uma água do mar sintética, recriando as espécies desaparecidas graças à biologia celular, despoluindo o ar por filtração. Prometiam-lhes uma humanidade incrementada, a transumanidade. Não haveria mais doenças, velhice, não haveria mais morte. Seria a hibridação entre o humano e a máquina.

"Mas ainda existirá uma condição humana? Ainda seremos capazes de dar um sentido à nossa existência?", perguntava-se um punhado de resistentes.

\footnotetext{
${ }^{14}$ Didática-criação: fotonovela e educação para os direitos (https://pedaradicale.hypotheses.org/3239).

${ }^{15}$ Didática-criação: ficção científica e filosofia da técnica (https://pedaradicale.hypotheses.org/3184).

${ }^{16}$ Didática-criação: O microconto filosófico - https://pedaradicale.hypotheses.org/3399
} 


\section{pro.posições}

http://dx.doi.org/10.1590/1980-6248-2021-0075

Os resistentes buscavam como descolonizar sua existência do agir técnico. Elas e eles pesquisavam, nas sabedorias antigas, que ética havia sido esquecida. Elas e eles pesquisavam na estética uma resistência à dominação da realidade instrumental.

Suas vozes e suas ações eram uma dissidência no coração dos empregos que lhes haviam sido designados pelo sistema. Elas e eles não cessavam de interrogar o sentido de agir contra o véu tecnológico. Elas e eles imaginavam outras ações para além daquelas prescritas pela racionalidade algorítmica.

Seremos, todavia, ainda capazes de ouvi-los e de nos juntar a eles antes que desapareçam, quando o sentido de seus combates terá se tornado para nós incompreensível?

\subsection{Foco sobre uma prática particular: o diálogo}

Sabe-se que o diálogo ocupa um lugar particular na perspectiva freiriana. Mas o diálogo pode tornar-se também uma forma de prática de didática-criação. Foi o que procuramos mostrar ao redigir um diálogo que mostra o interesse didático da escrita sob a forma dialógica:

\subsubsection{Por que escrevermos sob a forma do diálogo ${ }^{17}$}

\subsubsection{O diálogo em Paulo Freire}

Pergunta: O diálogo é uma noção central na pedagogia e na filosofia de Paulo Freire. Podemos retomar brevemente este ponto?

Resposta: A noção de diálogo foi desenvolvida por Paulo Freire a partir das obras de Martin Buber e de Karl Jaspers. O que remete a uma construção do sujeito, que não é monológico (como em Descartes ou Sartre), mas sim dialógico. Mas, em Paulo Freire, a noção de diálogo não impacta apenas a filosofia do sujeito, da consciência e do espírito. O diálogo possui também um apelo moral. Com efeito, a ação dialógica é uma ação na qual cada um é considerado como pessoa, o que evita a reificação. É neste aspecto que o diálogo se opõe à pedagogia bancária. Ele se opõe também às práticas antidialógicas: a manipulação, a divisão, a

${ }^{17}$ Texto publicado em Les cahiers de pédagogies radicales (maio de 2020): https://pedaradicale.hypotheses.org/2914. 


\section{pro.posições}

http://dx.doi.org/10.1590/1980-6248-2021-0075

conquista e a invasão cultural. Enfim, o diálogo, tanto em Freire quanto em Habermas, tem uma perspectiva democrática. De fato, a democracia repousa sobre uma ética da discussão.

Há, sem dúvida, uma fonte do diálogo que é menos explícita nas referências de Freire, que é a perspectiva socrática. Porque as animadoras e os animadores culturais sensatamente procuram colocar em prática um diálogo problematizante. O que significa um diálogo caracterizado por um questionamento que favoreça o processo de conscientização, em lugar de praticar monólogos revolucionários.

P: O próprio Paulo Freire usou o diálogo como forma de expressão, não foi?

R: Ele participou em várias obras que são redigidas como diálogos com outros interlocutores. Podemos citar, entre outras: “El miedo y la audácia”, Rio de Janeiro: Continuum, 1987 (com Ira Shor, republicado em 1996); ou ainda, Por una pedagogía de la pregunta. Ediciones del CREC (com Antonio Faundez).

\subsubsection{O diálogo em filosofia}

P: A forma dialógica é uma forma muito antiga em filosofia, mas relativamente em desuso hoje, não é?

R: Efetivamente, lembramos Sócrates, colocado em cena por Platão, o diálogo foi usado na história da filosofia durante muito tempo, até o final do século XVIII. Depois, caiu em desuso e não tem sido utilizada senão raramente, quase sempre com fins didáticos. Como exemplo, podemos citar a obra de Pascal Engel, La Dispute - Une introduction à la Philosophie Analytique (1997).

Podemos igualmente destacar que antigamente a escrita de diálogos era um tema no baccalauréat de filosofia ou nas provas de agrégation, e que isso desapareceu ${ }^{18}$. O que mostra o desuso no qual caiu essa forma de escrita.

A função do diálogo era a de colocar em cena, frequentemente, duas ou três posições filosóficas de modo a poder expô-las, ou mesmo com a intenção de refutá-las para defender sua própria posição. É o caso, por exemplo, nos Novos ensaios sobre o entendimento bumano, de Leibniz,

${ }_{18}$ Nota do tradutor (NT): o baccalauréat é um exame realizado na França ao final do ensino médio, enquanto a agrégation é um exame realizado quando se termina os estudos de graduação. 


\section{pro.posições}

http://dx.doi.org/10.1590/1980-6248-2021-0075

que consiste numa refutação da obra de John Locke. Às vezes, o diálogo pode assumir também uma forma mais aberta, mais cética, como é o caso dos diálogos aporéticos de Sócrates, ou, então, dos Diálogos sobre a religião natural, de Hume.

P: O discurso filosófico costuma ser criticado por ser redigido de modo obscuro. Isso é sempre assim?

R: Podemos destacar que até os séculos XVII e XVIII certos filósofos foram, ao contrário, modelos de clareza, em termos de expressão (temos, claro, que levar em conta as transformações da língua): é o caso, por exemplo, de Descartes ou de Rousseau. Hoje, há autores, principalmente na tradição analítica, que conseguem manter um alto nível de clareza linguística, com uma rigorosa exposição de argumentos. E não é o caso apenas de filósofos anglo-saxões; podemos pensar na França em Ruwen Ogien e na Alemanha em Markus Gabriel.

Há diferentes tipos de escrita em filosofia. Há tipos de escrita mais metafórica, que se aproximam da poesia; nesses casos, não se espera clareza, mas que dê a pensar. Há um estilo mais argumentativo, acompanhado por uma intensa busca de clareza, de distinção.

Se o objetivo do diálogo é o de ser claro, então é preciso adotar uma forma argumentativa. Mas podemos também imaginar diálogos que adotem um estilo mais literário, na medida em que o diálogo é igualmente uma forma de literatura. Nesse caso, podemos pensar no Suplemento à viagem de Bougainville, de Diderot, que é ao mesmo tempo um diálogo literário e filosófico.

P: Em que medida uma escrita sob a forma de diálogo pode ainda apresentar interesse para a reflexão filosófica?

R: No Teeteto, Sócrates afirma que "o pensamento é um diálogo da alma com ela mesma". Em si, o diálogo seria a própria forma do pensamento filosófico, em seu movimento de construção. O diálogo permite colocar em pauta questões de esclarecimento da proposta, mas também as objeções que podem ser feitas a uma tese. Ele permite manter um certo dinamismo na redação do pensamento. 


\section{pro.posições}

http://dx.doi.org/10.1590/1980-6248-2021-0075

\subsubsection{A redação do diálogo}

P: Certamente, há diversas maneiras de redigir um diálogo, segundo diferentes objetivos. Alguns podem ser mais literários, afastando-se de uma forma mais didática. Mas também é possível ter por objetivo alcançar a maior clareza da proposta. Podemos voltar aos procedimentos de escrita que podem favorecer tal objetivo de clareza?

R: Podemos, sem dúvida, distinguir diferentes procedimentos didáticos, dentre eles:

- O primeiro diz respeito às questões expositivas. São questões que trazem uma resposta que visa apresentar um ponto de uma doutrina. Pode haver diferentes questões expositivas encadeadas de modo lógico, num jogo de perguntas e respostas que possibilitem a exposição de uma teoria de modo coerente.

- O segundo procedimento são as questões que pedem argumentação. Tais questões têm por objetivo apresentar os argumentos para defender uma tese. Elas visam a apresentar um ou mais argumentos relativos a uma tese que é apresentada.

- O terceiro, são as questões-objeção. Elas possibilitam formular possíveis objeções a uma tese que é defendida no diálogo. Nesse caso, pode-se proceder analisando as objeções possíveis de serem feitas por outras teorias filosóficas (ou posições políticas, militantes etc.) sobre o objeto de reflexão abordado.

P: Qual o interesse das objeções na escrita dialógica?

R: Sem dúvida, as objeções são a dimensão mais interessante do diálogo, mas também a mais difícil. Porque é preciso praticar um "pensar contra si mesmo", imaginar as objeções que podem ser feitas a uma tese. O que pode levar a uma revisão de suas próprias posições sobre um dado assunto.

P: Qual poderia ser a armadilha do diálogo em relação à busca pela clareza do assunto?

R: O diálogo permite uma autonomia relativa de cada questão em relação às outras, permite inserir incisos. Mas é preciso, sem dúvida, estar atentos a não perder em clareza, perdendo a unidade e o encadeamento lógico das questões e das respostas que permitam ao leitor seguir o movimento de um pensamento em sua coerência interna. 


\section{pro.posições}

http://dx.doi.org/10.1590/1980-6248-2021-0075

\subsubsection{O diálogo em pedagogia crítica}

P: Qual o interesse específico que a forma dialógica apresenta para a pedagogia crítica?

R: A pedagogia crítica não pode ser uma forma de pensamento estático e dogmático. Ela deve ser capaz de levar em conta as objeções que the são feitas. O que significa não as calar e ser capaz de respondê-las. Significa também ser capaz de incorporá-las, se for necessário para se transformar e avançar.

Uma das tendências do pensamento militante pode ser o dogmatismo. A tendência a fixar-se de modo rígido em suas posições, sem de fato examinar as objeções adversas, a tendência a ignorar as objeções para se tranquilizar. Temos às vezes a impressão de que certos discursos continuam idênticos, sem nunca levar em conta as objeções, sem tomar o tempo necessário para as examinar e responder.

Os psicólogos cognitivos falam em dissonância cognitiva e em viés de confirmação. A dissonância cognitiva treina a mente humana para desconsiderar as informações que não se enquadrem em nosso plano de reflexão preestabelecido. $O$ viés de confirmação é a tendência da mente humana a não guardar senão as informações que estejam no sentido daquilo que já pensamos e a não reter as informações contrárias que poderiam nos levar a revisar nossas posições.

P: Qual poderia ser o posicionamento da pedagogia crítica em relação às temáticas de reflexão que ela pode abordar?

R: A pedagogia crítica implica em um certo quadro de reflexão que admita a pluralidade das opressões, a luta contra as discriminações e as desigualdades sociais. Mas, no interior desse quadro geral, pode haver uma diversidade de concepções: algumas de orientação mais marxista, outras ligadas à teoria queer, algumas ligadas às teorias feministas ou ainda ao pensamento decolonial etc. Contudo, a pedagogia crítica admite que a reflexão crítica pressupõe discutir e eventualmente recolocar em questão ideias relativamente admitidas habitualmente. Ainda que frequentemente o pensamento tenha a tendência de permanecer em sua zona de conforto, 


\section{pro.posições}

http://dx.doi.org/10.1590/1980-6248-2021-0075

continuando a afirmar aquilo que temos o hábito de defender e, sobretudo, aquilo que o grupo a que pertencemos tem o hábito de pensar. Às vezes, quando interrogamos pessoas sobre as razões pelas quais elas aderem a tal ou tal ideia, percebemos sua dificuldade de se justificar, pois em realidade trata-se de uma ideia admitida por um certo círculo. As ideias, então, fazem parte de elementos que são partilhados quando se pertence a um grupo, de modo a poder nele permanecer. Aceitar o risco de colocá-las em questão é assumir o risco de se isolar. A pedagogia crítica é, então, indissociável de uma coragem de pensar enquanto virtude moral e intelectual.

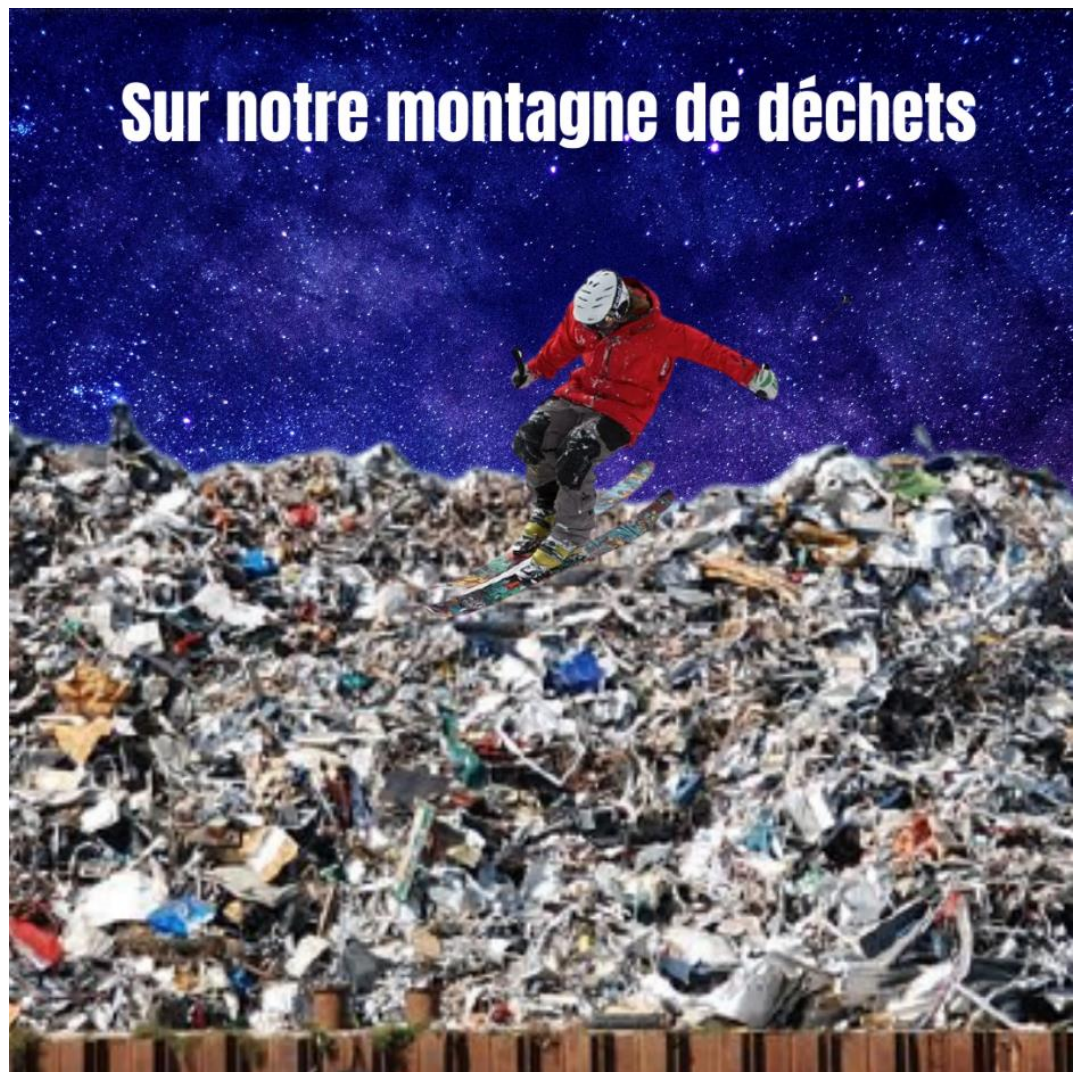

Figura 3 - Nossas montanhas de lixo

\subsection{Exemplos de aplicação da didática-criação}

A questão das técnicas utilizadas na didática-criação é um primeiro aspecto dessa abordagem. Mas igualmente precisamos colocar a questão das temáticas que podem ser abordadas em uma perspectiva de conscientização. Para fazer isso, daremos alguns exemplos de aplicações possíveis. 


\section{pro.posições}

http://dx.doi.org/10.1590/1980-6248-2021-0075

A criação de ficções críticas $^{19}$ : O objetivo aqui é o de utilizar a criação de ficções em uma perspectiva de pedagogia crítica, isto é, uma abordagem que vise a tomada de consciência das injustiças sociais sistêmicas e a encorajar a transformação orientada para a justiça social. Pode ser a criação de outros mundos possíveis, de mundos paralelos nos quais mudam apenas pequenos detalhes que mostram como poderia ser fácil cair num universo distópico, evidenciando a dimensão já distópica do mundo atual. Uma segunda abordagem consiste em selecionar certas dimensões presentes na realidade atual, exacerbando-as e apresentando suas limitações ligadas aos contra-poderes. Pode-se fazer refletir sobre as tendências atuais da sociedade. É possível ainda fazer uso da ironia e da sátira para se fazer aparecer a dimensão inaceitável da realidade social. As formas a serem utilizadas são particularmente o microconto ${ }^{20}$ ou a micronarrativa de ficção científica.

Da apresentação sonorizada de imagens (diaporama) à cápsula de vídeo: Uma das maneiras mais simples de produzir uma cápsula de vídeo é a de recorrer a um programa de diaporama ${ }^{21}$ para produzir uma apresentação de imagens sonorizada. No entanto, é possível interrogar-se sobre a possibilidade de retomar, no quadro da pedagogia crítica, as formas mais padronizadas de produção de apresentações sonoras e de cápsulas de vídeo para inspirar-se em outras estéticas. Podemos inclusive buscar inspiração em estéticas vanguardistas do começo do século XX que utilizavam a colagem, ou ainda do grafismo militante ${ }^{22}$.

Criação de anúncios falsos ${ }^{23}$ : Há diversas atividades de criação que podem tomar parte em uma educação crítica da publicidade. Uma primeira prática pode ser o desvio das publicidades (Toti, 2020), que se coloca na continuidade do situacionismo, sendo praticada, por exemplo, por Adbusters $^{24}$ ou ainda por Casseurs de Pub ${ }^{25}$. São práticas correntes de militantes da antipublicidade. A criação de anúncios falsos é praticada principalmente por artivistas. Por

\footnotetext{
19 Didática-criação: A ficção crítica na perspectiva da pedagogia radical (https://pedaradicale.hypotheses.org/3415).

${ }^{20}$ Didática-criação: O microconto filosófico (https://pedaradicale.hypotheses.org/3399).

${ }^{21}$ NT: Em português não é usual mencionar programa de diaporama, que nada mais são que programas de projeção tal como o PowerPoint.

22 Didática-criação: Criar capsulas de vídeo (https://pedaradicale.hypotheses.org/3351).

${ }^{23}$ Didática-criação: Criar anúncios falsos (https://pedaradicale.hypotheses.org/3271).

${ }^{24}$ NT: Adbusters Media Foundation é uma organização sem fins lucrativos, anticonsumista fundada em 1989 por Kalle Lasn e Bill Schmalz em Vancouver, Canadá (ver: https://www.adbusters.org/).

${ }^{25}$ NT: Associação criada em 1999, com o objetivo de promover a criação gráfica e artística baseada na crítica da sociedade de consumo e na promoção de alternativas (ver: http://www.casseursdepub.org/).
} 


\section{pro.posições}

http://dx.doi.org/10.1590/1980-6248-2021-0075

exemplo, em 2018, em Londres, um artista de rua difundiu falsos anúncios do Facebook para denunciar o escândalo da Cambridge Analytica. Também é uma prática utilizada na Itália pelo artista Hogre. Numa perspectiva de didática-criação, que visa a conscientização, trata-se de revelar as informações que a publicidade esconde, por exemplo, brincar com as técnicas de marketing, escarnecendo delas.

Lutar contra as discriminacõos com experiências conscientizadoras ${ }^{26}$ : tais experiências conscientizadoras podem tomar, por exemplo, a forma de cartazes ou ainda de vídeos. A perspectiva pedagógica que propusemos sob o nome de "experiência conscientizadora" apoiase sobre a concepção de vídeos conscientizadores. A criação de uma experiência conscientizadora tem por objetivo produzir sob a forma de um vídeo curto a experiência pela qual passa uma pessoa durante um processo de conscientização.

\subsection{A dimensão de empoderamento da didática-criação}

A dimensão de empoderamento da didática-criação intervém em diferentes níveis. $\mathrm{O}$ primeiro consiste na possibilidade de permitir a expressão criativa para desenvolver a capacidade de fazer ouvir uma voz diferente, combatendo assim a cultura do silêncio. Pela expressão criativa crítica, trata-se de desenvolver a coragem moral de exprimir uma voz diferente frente aos empreendimentos do discurso neoliberal dominante de deslegitimação do ideário utópico. De fato, criar um suporte em didática-criação implica em desenvolver a coragem entre as e os participantes para se exprimirem de maneira crítica através de um meio de criação estética.

As produções das e dos participantes podem ser retomadas na animação das discussões críticas. Além disso, as produções realizadas individual e/ou coletivamente podem dar origem a uma exposição que pode servir de suporte para a instauração de discussões críticas. Por fim, as produções realizadas, por exemplo, as visuais, podem ser utilizadas no contexto de protestos públicos. As imagens criadas podem ser coladas no espaço público para provocar a reflexão coletiva ou para desafiar. Elas também podem ser colocadas em cartazes durante as manifestações de protesto.

26 Perspectiva pedagógica: Lutar contra as discriminações através de experiências conscientizadoras (https://pedaradicale.hypotheses.org/3169). 


\section{pro.posições}

http://dx.doi.org/10.1590/1980-6248-2021-0075

\section{Discussão dos limites de emancipação da didática-criação}

Como lembramos na introdução, não devemos, em nossa opinião, confundir a pedagogia crítica, que envolve a ação ética, e as variações didáticas que dela podem ser feitas, que comportam uma dimensão técnica. Desse ponto de vista, seria errado pensar que uma variação didática, mesmo que não apenas do ponto de vista técnico, mas também do ponto de vista estético, poderia constituir um baluarte suficiente contra o tecnocapitalismo.

Jean-Miguel Pire, em Otium (Pire, 2020), lembra acertadamente que a atividade artística faz parte de uma forma de ação que afasta os valores instrumentais do capitalismo. Por isso, defende a implantação de uma cultura artística na escola que permita legitimar outra relação com o mundo para lutar contra a hegemonia do utilitarismo neoliberal. No entanto, do nosso ponto de vista, a ação estética não permite lutar contra a lógica neoliberal se não for guiada e normalizada pela ação ética. Isso é o que mostraremos a seguir.

\subsection{O exemplo da narrativa digital}

A história da narrativa digital é uma narrativa em si que nos mostra como qualquer técnica, mesmo que originalmente a serviço dos oprimidos, pode ser assumida pelo sistema capitalista. Porque o que torna uma prática educativa emancipatória, ou carrega um projeto emancipatório, não está na própria técnica. Está no projeto, na intenção ética, desta pedagogia.

A técnica, mesmo para fins artísticos, como na narrativa digital, não é em si uma fonte de emancipação. Originalmente, a narrativa digital surgiu da existência, com o mundo digital, de novos softwares que possibilitaram que pessoas sem habilidades técnicas específicas se expressassem facilmente: apresentação de slides, vídeo digital, fotografia digital etc. As técnicas desenvolvidas na narrativa digital foram inspiradas principalmente em um documentário: The Civil War, de Ken Burns, que utilizou a imagem estática fotográfica com zooms e panorâmicas (Ferster et al., 2006, p. 147).

O StoryCenter desenvolveu toda uma metodologia para encorajar públicos socialmente desfavorecidos a contar histórias sobre suas vidas. Esta abordagem é usada, por exemplo, na Bélgica, por Maks Vzw. É usada com migrantes, grupos vítimas de discriminação, prisioneiros etc. No entanto, a eficácia desses contos, baseados na subjetividade e na emoção, tem levado ao 


\section{pro.posições}

http://dx.doi.org/10.1590/1980-6248-2021-0075

seu reaproveitamento pelo mundo corporativo como marketing e com finalidade de promoção de marcas. Essa abordagem também é usada na educação neoliberal para promover a motivação e o engajamento dos alunos.

O que faz, então, a diferença entre essas práticas e a abordagem inicial? O que faz a diferença é que a narração de histórias originalmente digital pretendia ser um processo de empoderamento de pessoas socialmente oprimidas, de modo a devolver-lhes voz e, portanto, dignidade, tornando-as narradoras e narradores de suas próprias histórias, especialmente aquelas em situações de opressão, como as e os migrantes.

Portanto, não são as técnicas que distinguem a versão emancipatória da versão neoliberal da narrativa digital, mas o contexto de implementação e o projeto ético-político que a impulsiona. Muitas vezes acontece que pessoas em busca de uma concepção e práticas emancipatórias em educação pensem que o caráter emancipatório de uma pedagogia está em suas técnicas, na ação técnica. Na realidade, porém, o caráter emancipatório de uma pedagogia reside no agir ético. O recurso às práticas artísticas certamente leva a um distanciamento do agir utilitarista estrito. Mas ele não basta para lutar contra o domínio da racionalidade instrumental capitalista.

\subsection{A "virada ética" da arte contemporânea}

Em O Novo Espirito do Capitalismo, (Boltanski \& Chiapello, 1999) propõem a recuperação da crítica artística pelo capitalismo. Também encontramos essa recuperação por meio do uso que se faz da noção de criatividade (Mas, 2018), promovida pela Organização para a Cooperação e Desenvolvimento Econômico (OCDE), como uma das quatro competências do século XXI. Outros trabalhos também analisaram a maneira pela qual a pesquisa-criação, que usa práticas artísticas na pesquisa científica, leva à instrumentalização da arte pelo capitalismo, ao promover a aceitação social de novas tecnologias (Citton, 2018).

A dimensão técnica da criação artística esteve presente desde a Antiguidade até o final da Idade Média: o artista e o artesão não se distinguiam. A arte refere-se tanto à produção técnica quanto à produção artística. A noção de arte, portanto, inclui uma dimensão de realização técnica (exceto em certos casos limítrofes de arte conceitual) que perdura ainda hoje. Como Marx mostrou, o capitalismo, como qualquer modo de produção, depende do desenvolvimento 


\section{pro.posições}

http://dx.doi.org/10.1590/1980-6248-2021-0075

técnico. Atualmente, a fase neoliberal do capitalismo é indissociável do desenvolvimento das tecnologias digitais e das formas de racionalidades técnicas que elas implementam. Assim, seja Max Weber ou a Escola de Frankfurt, esses autores mostraram como a racionalidade técnica é inerente ao modo de produção capitalista. Em geral, a técnica é um meio eficaz de atingir um objetivo. Como resultado, o capitalismo tende a recuperar tudo o que apresenta uma eficiência técnica.

Outros autores têm apontado como, no capitalismo, desde o século XX, com o desenvolvimento do design, ocorreu uma recuperação da estética a serviço do capital (Lipovetsky \& Serroy, 2013). A arte é usada aqui por sua capacidade de produzir técnicas estéticas destinadas a atrair os consumidores e as consumidoras. No entanto, é possível perceber atualmente na sociedade um movimento de questionamento do domínio da racionalidade instrumental pela ação ética. O questionamento atual da relação entre arte e ética vem de duas dimensões. A primeira é que a arte que, no entanto, parece referir-se a valores não utilitários, se viu instrumentalizada pelo capitalismo. A arte não tem conseguido preservar sua autonomia em relação ao capital: por exemplo, a questão do mercado da arte com a explosão da especulação sobre as obras de certos artistas é testemunha.

Portanto, é bastante significativo que no mundo da arte se encontrem tentativas de se organizar, lutando contra essas lógicas de trabalho, e também opondo-as a uma ética nas relações de trabalho. A esse respeito, podemos citar, por exemplo, o artista plástico Guillaume Maraud, convidado de um programa em 2019, "Interdire d'interdire - Qual a função da arte contemporânea?”, quando afirmou: “Talvez nos situemos menos em questões de estética, mas mais em questões de ética, colocando as relações de dominação no centro... A minha geração... enfrenta principalmente formas de trabalho gratuito... Por outro lado, acredito que existam soluções coletivas que estão surgindo... que propõem tabelas salariais para os trabalhadores da arte...".

Guillaume Maraud alude então, dentre outros, ao coletivo La Buse, que escreve em seu site: 


\section{pro.posições}

http://dx.doi.org/10.1590/1980-6248-2021-0075

La Buse reúne artistas, autores/as, pesquisadores/as, designers gráficos, críticos, curadores/as, professores/as, produtores/as, tradutores/as... em torno de questões de trabalho e de ética no campo da arte... La Buse questiona o sistema econômico da arte, os atuais mecanismos de remuneração de seus atores e atrizes, seus estatutos, bem como as questões éticas relativas ao poder e seus abusos: comportamento impróprio de natureza sexual ou moral, discriminação, conflito de interesses e mais genericamente as situações de desigualdades mantidas pelo desconhecimento e/ou não respeito da lei. ${ }^{27}$

Aqui, novamente, percebemos a vontade de buscar em uma ética da crítica os limites da lógica capitalista e das relações sociais de dominação em geral. Na verdade, podemos perceber com clareza: se as técnicas artísticas, inclusive as utilizadas com finalidade crítica, bastassem para ser uma forma de emancipação, os oprimidos do mundo da arte não estariam tentando buscar na ética amparo para tentar limitar relações de dominação neste mundo. Assim, podemos duvidar fortemente que a criação de ferramentas educacionais inovadoras, vinculadas às práticas artísticas, possam fazer parte de um caminho de emancipação, se não estiverem fortemente vinculadas a uma práxis (agir ético).

\section{Conclusão}

Este artigo permitiu-nos evidenciar um conjunto de práticas didáticas, baseadas na criação estética, que desenvolvemos sob o nome de "didática-criação" e que incluímos na continuidade da pedagogia crítica de Paulo Freire. No entanto, também mostramos muito claramente que o desenvolvimento de práticas técnicas, mesmo quando afirmam fazer parte de uma criação artística, não pode ser suficiente para lutar contra as capturas capitalistas e o uso indevido das ferramentas produzidas. É por isso que a pedagogia crítica, resultante da obra de Paulo Freire, não pode ser confundida e reduzida a uma didática. Deve ser pensada, fundamentalmente, como um ato ético, como o próprio Paulo Freire repetidamente afirmou.

${ }^{27}$ Ver: https://la-buse.org/ 


\section{pro·posições}

http://dx.doi.org/10.1590/1980-6248-2021-0075

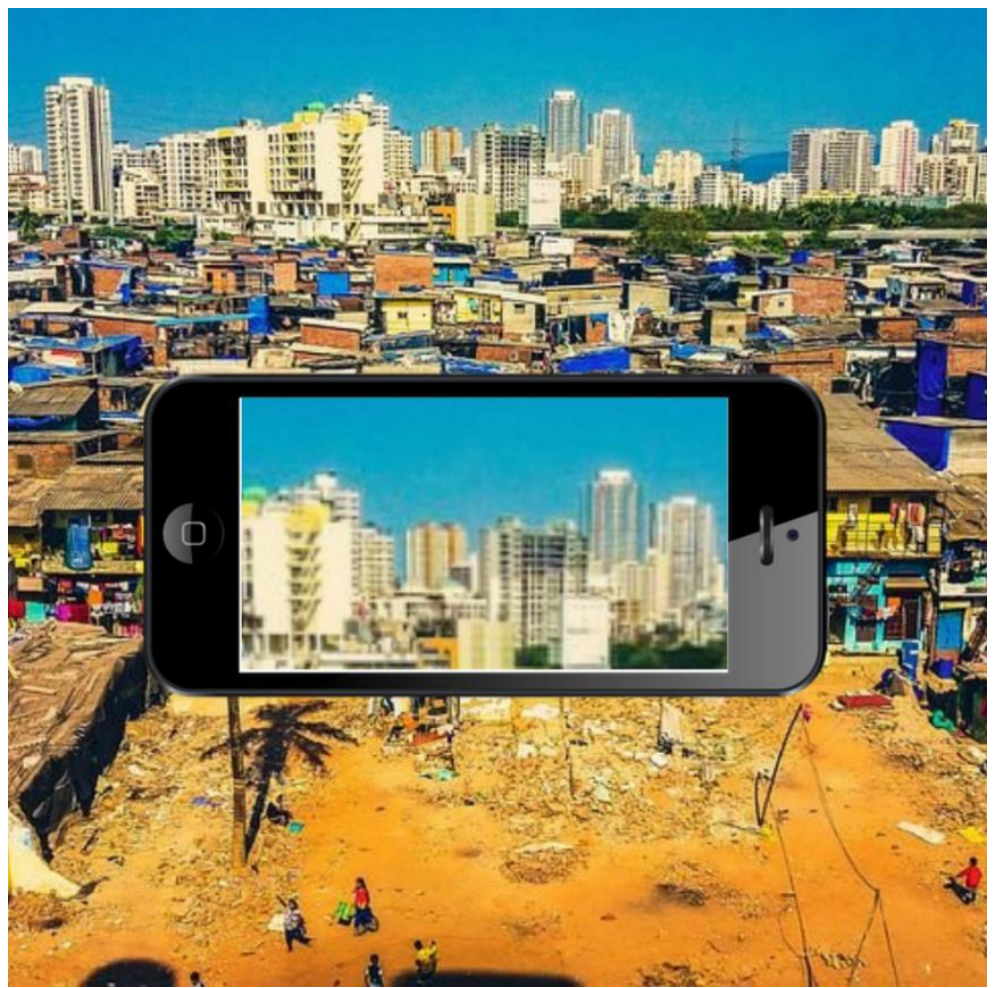

Figura 4 - Favela ou megalópole

\section{Referências}

Benjamin, W. (2013). L'cuvre d'art à l'époque de sa reproductibilité technique. Payot.

Boal, A. (2009). A estética do oprimido. Garamond.

Boltanski, L., \& Eve, C. (1999). Le nowvel esprit du capitalisme. Gallimard.

Citton Y. (2018). Post-scriptum sur les sociétés de recherche-création. In E. Manning \& B. Massumi, Pensée en acte: vingt propositions pour la recherche-création (A. Chrétien, Trad., pp. 95125). Les Presses du Réel.

Ferster, B., Hammond, T., \& Bull, G. (2006). Primary access: Creating digital documentaries in the social studies classroom. Social Education, 70(3), 147. http://www.viseyes.org/primaryaccess/PrimaryAccessArticle.pdf

Freire P. (1971). Vision du monde. In G. Tolini (Org.), Conscientisation, recherche de Paulo Freire (pp. 20-23). Éditions d'Alsace.

Freire, P. (1974). Pédagogie des opprimés. Maspero. 


\section{pro.posiçções}

http://dx.doi.org/10.1590/1980-6248-2021-0075

Freire, P. (1979). Conscientização: Teoria e prática da libertação - uma introdução ao pensamento de Paulo Freire. Cortez \& Moraes.

Freire, P. (2013). Pédagogie de l'autonomie. Érès.

Freire, P. (2019). El maestro sin recetas: el desafio de enseñar en un mundo cambiante (T. Arijon, Trad., pp. 49-80). Siglo XXI.

Giacco, G., Didier, J., Chatelain, S., \& Verry, F. (2020). Définir l'identité de la recherche-création: état des lieux et au-delà. EME.

Giroux, H. A., \& McLaren, P. (1997). Paulo Freire, postmodernism and the utopian imagination: a Blochian reading. In J. O. Daniel \& T. Moylan (Eds.), Not yet: Reconsidering Ernst Bloch (pp.138-162). Verso Press.

Habermas J. (1987). Théorie de l'agir communicationnel (J.-M. Ferry, Trad.). Fayard.

Lipovetsky G., Serroy J. (2013). L'esthétisation du monde: Vivre à l'âge du capitalisme artiste. Gallimard.

Mas J.Y. (2018). De la critique artiste du capitalisme à la critique pédagogique de l'école. In L.

De Cock \& I. Pereira. Les pédagogies critiques. Agone.

Pereira I. (2019). L'éthique de la critique, un impératif pour les pédagogies radicales. Les cabiers de pédagogies radicales, 1. https://pedaradicale.hypotheses.org/3015

Pire, J.-M. (2020). Otium. Actes Sud.

Toti, J.-F. (2020). Détournement publicitaire militant: quels impacts sur la marque détournée? Revue de l'organisation responsable, 15(2), 17-28.

Vandette, M.-P., Gosselin, J., \& Valiquette-Tessier, S.-C (2014). Vers la réussite: utilisation de Photovoice pour témoigner de l'expérience des mères monoparentales vivant dans un contexte défavorisé. Nouvelles pratiques sociales, 27(1), 168-188.

\section{Dados da submissão:}

Submetido à avaliação em 08 de junho de 2021; aceito para publicação em 03 de julho de 2021.

Autor correspondente: Inspe de l'Académie de Créteil. Rue Jean Macé, 94380, Bonneuil sur Marne, France. 